\title{
MT5-MMP, just a new APP processing proteinase in Alzheimer's disease?
}

\author{
Kévin Baranger, Michel Khrestchatisky and Santiago Rivera* (D)
}

\begin{abstract}
We have recently identified in a transgenic mouse model of Alzheimer's disease (AD) membrane-type 5-MMP (MT5-MMP) as a new player in Alzheimer's pathogenesis, which displays pro-amyloidogenic features and proteolytic processing of amyloid precursor protein (APP). Another group has reported that MT5-MMP processing of APP may release a novel neurotoxic APP fragment. Although MT5-MMP-mediated APP processing appears to be a key pathogenic step, we hypothesize that MT5-MMP may also contribute to AD pathogenesis through complementary mechanisms that involve the activation of pro-inflammatory pathways and/or APP trafficking.
\end{abstract}

Keywords: Matrix metalloproteinases, Neurodegenerative disease, Trafficking, Neuroinflammation, IL-1 $\beta$, Amyloidogenesis, Amyloid precursor protein

\section{Background}

MT5-MMP belongs to the multigenic family of $\mathrm{Zn}^{2+}$ MMPs, which have been extensively associated with different physiological and pathological settings $[1,2]$. MT5-MMP was first isolated from mouse brain tissue and from glioblastoma by two laboratories in 1999 [3, 4]. MT5-MMP is predominantly expressed in the nervous system [5], mainly in neurons, and to a lesser extent also in astrocytes and microglial and endothelial cells [6-8]. MT5-MMP is a 645 amino acid transmembrane glycosylated proteinase that is intracellularly activated by the $\mathrm{Ca}^{2+}$-dependent proprotein convertase furin. The latter can also cleave MT5-MMP above its transmembrane domain before it reaches the plasma membrane, thus leading to the release of a truncated active soluble form of MT5-MMP [9]. MT5-MMP harbors nuclear localization sequences that may tag the proteinase for import into the nucleus [10]. The proteolytic activity of MT5-MMP is mainly under the control of the endogenous tissue inhibitor of MMP-2 (TIMP-2). Alternatively, adaptor proteins such as Mint-3 regulate MT5-MMP activity by controling its recycling from the trans-golgi network to the cell membrane and its localization in cells [11]. Moreover, MT5-MMP can be targeted to synapses through interaction with proteins containing PDZ domains such as

\footnotetext{
* Correspondence: santiago.rivera@univ-amu.fr
}

Aix Marseille Univ, CNRS, NICN, Marseille, France the AMPA receptor binding protein $(\mathrm{ABP})$ and the glutamate receptor interacting protein (GRIP) [12]. Overall, MT5-MMP appears as a functionally versatile molecule by virtue of its multiple interactions and localizations in the intracellular and pericellular compartments. An open question is whether MT5-MMP may in turn influence the subcellular localization and activity of its interacting proteins, and should be considered as a "moonlighting protein." One recent example among MMPs concerns MMP-12, which besides its well-known proteolytic activity has also transcription factor properties [13].

We are just starting to understand the functional diversity of MT5-MMP in pathology. Early studies showed the ability of MT5-MMP to proteolytically activate MMP-2 [3] and to process KiSS-1 protein and KISS-1-derived decapeptide metastin [14], which overall promotes cancer progression. MT5-MMP has been also reported to stimulate neuropathic pain by promoting aberrant axonal sprouting in the spinal cord after sciatic nerve injury in mice [15]. Moreover, it has been suggested that MT5-MMP is necessary for the inflammatory response to interleukin-1 beta (IL-1 $\beta$ ) and tumor necrosis factor-alpha (TNF- $\alpha$ ) in the peripheral nervous system [16]. It is noteworthy that no overt developmental abnormalities have been detected in MT5-MMP ${ }^{-/-}$mice, in contrast with the clearly marked phenotypes they display in pathological conditions [15-17], and also in 


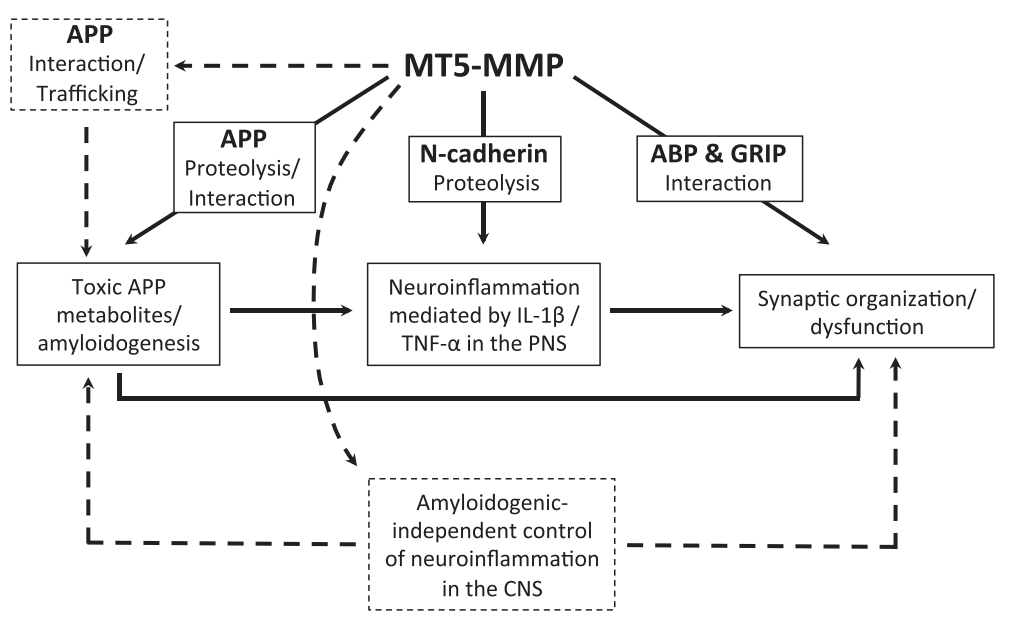

Fig. 1 Scheme summarizing some known and some hypothetical functions of MT5-MMP in nervous system pathophysiology. Solid lines/frames represent biological actions and functional interactions reported in the literature. Dotted lines/insets represent the alternative/complementary hypotheses we propose herein. APP: amyloid precursor protein; ABP: AMPA receptor binding protein; CNS: central nervous system; GRIP: glutamate receptor interacting protein; IL-1 $\beta$ : interleukin-1 beta; PNS: peripheral nervous system; TNF-a: tumor necrosis factor-alpha

contrast with other members of the MT-MMP family such as MT1-MMP. This could imply that modulating MT5-MMP activity in pathology may have limited impact on physiology and highlights the therapeutic potential of targeting MT5-MMP.

\section{MT5-MMP in Alzheimer's disease}

MT5-MMP was first related to AD in a study showing the expression of the proteinase in dystrophic neurites around senile plaques in post-mortem AD brains [18]. The ability of MT5-MMP to process APP into different truncated APP fragments was later demonstrated [19]. More recently, two teams, including ours, reported the possible implication of MT5-MMP in AD by means of its functional interaction with APP [17, 20]. Willem and collaborators showed that MT5-MMP cleavage of APP upstream of the beta-site amyloid precursor protein cleaving enzyme 1 (BACE-1), combined with cleavage by the $\alpha$-secretase ADAM-10, generates a so-called A $\eta-\alpha$ fragment, which inhibits long-term potentiation (LTP) in vitro [20]. In parallel, we provided in vivo evidence that MT5-MMP deficiency is associated with a robust and durable amelioration of the pathological outcome in the $5 \mathrm{xFAD}$ transgenic mouse model of $\mathrm{AD}$. Compared to 5xFAD mice, bigenic 5xFAD/MT5-MMP ${ }^{-/-}$exhibited strong decreases of amyloid beta peptide $(\mathrm{A} \beta)$ load, gliosis and IL-1 $\beta$ levels, and a better preservation of the neuronal network. Moreover, cognitive and LTP dysfunctions were prevented in bigenic mice [17]. In the same study, we demonstrated that MT5-MMP interacts with APP and stimulates the formation of $A \beta$ and the toxic C99 APP fragment. Together, these results unveil the contribution of MT5-MMP to AD pathogenesis and strongly suggest its involvement at least in APP processing. However, two complementary non-exclusive mechanistic hypotheses may be put forward on the pathogenic effects of MT5-MMP in AD:

\section{Hypotheses}

(1) The pro-amyloidogenic features of MT5-MMP could result from interactions with APP, which would stimulate its trafficking into endosomes, not necessarily in a proteolytic-dependent manner. These organelles are considered to be the main loci of $A \beta$ production [21]. Testing this hypothesis would require to modulate the activity/presence of MT5MMP by gain/loss of function in a cellular system and determine by imaging and biochemical approaches how this might change the distribution of APP and/or A $\beta$ species in the endosomal/ lysosomal compartments.

(2) The pathogenic role of MT5-MMP in AD could also result from its contribution to the chronic neuroinflammatory process that aggravates $\mathrm{AD}$ pathogenesis. Reduced glial reactivity and IL-1 $\beta$ levels found in our bigenic 5xFAD/MT5-MMP ${ }^{-/-}$ mice [17] could simply result from MT5-MMP deficiency and consequent reduced $A \beta$ load, but we cannot exclude that MT5-MMP inhibition could actually reduce neuroinflammation in an amyloid-independent manner. This idea is consistent with the two following findings: (a) intraplantar injections of IL- $1 \beta$ or TNF- $\alpha$ in MT5-MMP ${ }^{-/-}$ mice do not induce the pro-inflammatory response commonly observed in wild-type mice [16]. The underlying mechanism involves a deficient processing of N-cadherin, which is a substrate of MT5-MMP, 
and this appears to alter the communication between mast cells and peripheral sensory neurons. (b) The combined proteolytic action of MT5-MMP and $\alpha$-secretase on APP can release under certain conditions a $\mathrm{N}$-terminally elongated $\mathrm{A} \beta$ form, the

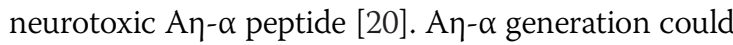
have a neuroinflammatory effect associated with its neurotoxicity, but also a consubstantial reduction of the pool of soluble APP- $\alpha$ (sAP $\alpha)$ generated by the solely action of $\alpha$-secretase, and reported to be neuroprotective [22]. Whether MT5-MMP exerts pro-inflammatory activity in the brain could be tested by challenging neural cell cultures deficient for MT5-MMP with pro-inflammatory agents and determine whether well-known responsive genes are transcriptionally activated. Alternatively, the same experimental readout could be used after icv administration of the cytokines of interest in MT5-MMP ${ }^{-1-}$ brains. This idea could be further tested in young bigenic 5xFAD/MT5-MMP ${ }^{-/-}$ mice before $A \beta$ accumulation.

\section{Implications of the hypotheses}

The confirmation of the first hypothesis will uncover MT5-MMP as a multifunctional enzyme with proteolytic and non-proteolytic features, which could both ultimately stimulate APP metabolism and amyloidogenesis. The confirmation of the second hypothesis would add MT5-MMP to the list of MMPs that promote inflammation in the central nervous system and most interestingly would indirectly support the idea that neuroinflammation is a triggering event of the pathogenic process in $\mathrm{AD}$. Confirming both hypotheses should place MT5-MMP at the crossroads of amyloidogenesis and neuroinflammation, thus providing ground for a better comprehension of $\mathrm{AD}$ pathophysiology (see Fig. 1). In turn, such confirmation would pave the way for the development of innovative therapeutic strategies based on the modulation of MT5MMP, which should take into account the diversity of its biological actions.

\section{Abbreviations}

5xFAD, transgenic mice expressing 5 human familial Alzheimer's disease mutations; $A \beta$, amyloid beta peptide; $A B P$, AMPA receptor binding protein; ADAM-10, a disintegrin and metalloproteinase-10; APP, amyloid precursor protein; BACE-1, beta-site amyloid precursor protein cleaving enzyme 1; GRIP, glutamate receptor interacting protein; IL-1 $\beta$ : interleukin-1 beta; LTP, long-term potentiation; MMPs, matrix metalloproteinases; MT5-MMP, membrane-type 5-MMP; TIMP-2, tissue inhibitor of MMPs-2; TNF-a, tumor necrosis factor-alpha

\section{Acknowledgements}

Not applicable.

\section{Funding}

This work was supported by funding from the CNRS and Aix-Marseille Université and by grants from the French National Agency for Research (ANR) to SR (MAD5) and to MK (PREVENTAD). The work was also supported by grants from LECMA and France Alzheimer to SR and MK. KB was granted a Research Associate fellowship by the French "Fondation Plan Alzheimer" and Aix-Marseille Université A*MIDEX (Management of Talents).

Availability of data and materials

Not applicable.

\section{Authors' contributions}

$\mathrm{KB}, \mathrm{MK}$, and SR participated to the conception of the present hypotheses. All authors read and approved the final manuscript.

\section{Author's information}

$\mathrm{KB}$ is a Research Associate at Aix-Marseille Université

MK is Director of Research at CNRS and director of the NICN laboratory.

SR is Director of Research at CNRS and director of the Neural Degeneration and Plasticity team.

Competing interests

The authors declare that they have no competing interests.

Consent for publication

Not applicable.

Ethics approval and consent to participate

Not applicable.

Received: 24 May 2016 Accepted: 20 June 2016

Published online: 28 June 2016

\section{References}

1. Rivera S, Khrestchatisky M, Kaczmarek L, Rosenberg GA, Jaworski DM. Metzincin proteases and their inhibitors: foes or friends in nervous system physiology? J Neurosci. 2010;30:15337-57. doi:10.1523/JNEUROSCI.3467-10.2010.

2. Baranger $\mathrm{K}$ et al. Endogenous and synthetic MMP inhibitors in CNS physiopathology. Progr Brain Res. 2014;214:313-51. doi:10.1016/B978-0-444-63486-3.00014-1.

3. Llano $E$ et al. Identification and characterization of human MT5-MMP, a new membrane-bound activator of progelatinase a overexpressed in brain tumors. Cancer Res. 1999;59:2570-6.

4. Pei D. Identification and characterization of the fifth membrane-type matrix metalloproteinase MT5-MMP. J Biol Chem. 1999;274:8925-32.

5. Jaworski DM. Developmental regulation of membrane type-5 matrix metalloproteinase (MT5-MMP) expression in the rat nervous system. Brain Res. 2000;860:174-7

6. Hayashita-Kinoh $\mathrm{H}$ et al. Membrane-type 5 matrix metalloproteinase is expressed in differentiated neurons and regulates axonal growth. Cell Growth \& Differ. 2001:12:573-80.

7. Lafleur MA, Handsley MM, Knauper V, Murphy G, Edwards DR. Endothelial tubulogenesis within fibrin gels specifically requires the activity of membrane-type-matrix metalloproteinases (MT-MMPs). J Cell Sci. 2002;115: 3427-38.

8. Warren KM, Reeves TM, Phillips LL. MT5-MMP, ADAM-10, and N-cadherin act in concert to facilitate synapse reorganization after traumatic brain injury. J Neurotrauma. 2012;29:1922-40. doi:10.1089/neu.2012.2383.

9. Wang $X$, Pei D. Shedding of membrane type matrix metalloproteinase 5 by a furin-type convertase: a potential mechanism for down-regulation. J Biol Chem. 2001;276:35953-60. doi:10.1074/jbc.M103680200.

10. Gueye $Y$ et al. Trafficking and secretion of matrix metalloproteinase-2 in olfactory ensheathing glial cells: a role in cell migration? Glia. 2011;59:750-70. doi:10.1002/glia.21146.

11. Wang $P$, Wang $X$, Pei D. Mint-3 regulates the retrieval of the internalized membrane-type matrix metalloproteinase, MT5-MMP, to the plasma membrane by binding to its carboxyl end motif EW. J Biol Chem. 2004; 279:20461-70. doi:10.1074/jbc.M400264200.

12. Monea S, Jordan BA, Srivastava S, DeSouza S, Ziff EB. Membrane localization of membrane type 5 matrix metalloproteinase by AMPA receptor binding protein and cleavage of cadherins. J Neurosci. 2006:26:2300-12. doi:10.1523/JNEUROSCI.3521-05.2006.

13. Marchant DJ et al. A new transcriptional role for matrix metalloproteinase-12 in antiviral immunity. Nat Med. 2014;20:493-502. doi:10.1038/nm.3508. 
14. Takino T et al. Cleavage of metastasis suppressor gene product KiSS-1 protein/metastin by matrix metalloproteinases. Oncogene. 2003;22:4617-26. doi:10.1038/sj.onc.1206542.

15. Komori K et al. Absence of mechanical allodynia and Abeta-fiber sprouting after sciatic nerve injury in mice lacking membrane-type 5 matrix metalloproteinase. FEBS Lett. 2004;557:125-8.

16. Folgueras AR et al. Metalloproteinase MT5-MMP is an essential modulator of neuro-immune interactions in thermal pain stimulation. Proc Natl Acad Sci U S A. 2009;106:16451-6. doi:10.1073/pnas.0908507106.

17. Baranger $\mathrm{K}$ et al. MT5-MMP is a new pro-amyloidogenic proteinase that promotes amyloid pathology and cognitive decline in a transgenic mouse model of Alzheimer's disease. Cell Mol Life Sci. 2016;73:217-36. doi:10.1007/s00018-015-1992-1.

18. Sekine-Aizawa $Y$ et al. Matrix metalloproteinase (MMP) system in brain: identification and characterization of brain-specific MMP highly expressed in cerebellum. Eur J Neurosci. 2001;13:935-48.

19. Ahmad $\mathrm{M}$ et al. Cleavage of amyloid-beta precursor protein (APP) by membrane-type matrix metalloproteinases. J Biochem. 2006;139:517-26. doi:10.1093/jb/mvj054.

20. Willem, M. et al. eta-Secretase processing of APP inhibits neuronal activity in the hippocampus. Nature. 2015. doi:10.1038/nature14864.

21. Rajendran $L$, Annaert W. Membrane trafficking pathways in Alzheimer's disease. Traffic. 2012;13:759-70. doi:10.1111/j.1600-0854.2012.01332.x.

22. Nhan HS, Chiang K, Koo EH. The multifaceted nature of amyloid precursor protein and its proteolytic fragments: friends and foes. Acta Neuropathol. 2015:129:1-19. doi:10.1007/s00401-014-1347-2.

\section{Submit your next manuscript to BioMed Central} and we will help you at every step:

- We accept pre-submission inquiries

- Our selector tool helps you to find the most relevant journal

- We provide round the clock customer support

- Convenient online submission

- Thorough peer review

- Inclusion in PubMed and all major indexing services

- Maximum visibility for your research

Submit your manuscript at www.biomedcentral.com/submit

) Biomed Central 